\title{
Sustainable Concretes for Structural Applications
}

\author{
Luigi Biolzi, Sara Cattaneo, Gianluca Guerrini and Vahid Afroughsabet
}

\begin{abstract}
For the production of a high-performance concrete (HPC) matrix, a large amount of binder is normally used. The production of ordinary Portland cement (OPC) as the binder of concrete accounts for $7 \%$ of $\mathrm{CO}_{2}$ emission, which has notable environmental impacts, and subsequently results in unsustainable concrete. The aim of the present study was to investigate the effect of replacing OPC with calcium sulfoaluminate cement (CSA) or ground granulated blast-furnace slag (GGBS) as sustainable binders on the engineering properties of HPC. Additionally, the effect of introducing double hooked-end (DHE) steel fibers at a fiber volume fraction of $1 \%$ on the properties of HPC was assessed. The compressive strength, splitting tensile strength, flexural strength, and modulus of elasticity of HPC were evaluated. Moreover, a scanning electron microscopy (SEM) method was used to study the microstructure of the concretes. The results indicate that the replacement of OPC with CSA cement results in an improvement in the mechanical properties of HPC particularly at later ages of curing, while combination CSA cement with OPC and GGBS in the binary and ternary systems degrades the concrete's strengths. The addition of $1 \%$ DHE steel fibers significantly increased the engineering properties of concrete. The results show that the bond between a cement matrix and steel fibers has been enhanced due to the expansive behavior of CSA cement. The SEM observation also shows the significant influence of CSA cement on the microstructure of concrete by forming a rich amount of ettringite which subsequently results in an improvement in the properties of concrete.
\end{abstract}

L. Biolzi · S. Cattaneo $(\bowtie)$

Architecture, Built Environment and Construction Engineering-ABC Department, Politecnico di Milano, Milan, Italy

e-mail: sara.cattaneo@polimi.it

G. Guerrini

Milan, Italy

V. Afroughsabet

Department of Civil Engineering, University of Toronto, Toronto, Canada

(C) The Author(s) 2020

S. Della Torre et al. (eds.), Regeneration of the Built Environment

from a Circular Economy Perspective, Research for Development,

https://doi.org/10.1007/978-3-030-33256-3_24 
Keywords High-performance concrete $\cdot$ Calcium sulfoaluminate cement (CSA) • Granulated blast-furnace slag (GGBS) • Double hooked-end steel fibers • Mechanical properties $\cdot$ SEM observation

\section{Introduction}

Portland cement concrete is the most widely used human-made material on the planet; around 25 billion metric tons are produced globally each year (Celik et al. 2014). Recently, the demand for using high-performance concrete (HPC) has widely increased throughout the world. As is commonly known, for the production of an HPC matrix, a large amount of binder is normally used. Even though the reasons for concrete's dominance are diverse, the massive production and consumption cycle of concrete have a significant environmental impact, making the concrete industry unsustainable. Currently, Portland cement concrete production accounts for around $7 \%$ of carbon dioxide $\left(\mathrm{CO}_{2}\right)$ emissions annually. Most of the emissions are attributable to the production of ordinary Portland cement (OPC) clinker. The current approach to overcome this problem is through the reducing clinker factor and through replacing OPC with supplementary cementitious materials such as fly ash, slag, silica fume, and natural pozzolan (Gartner \& Hirao 2015). However, due to growing field experience and increasing demand for those materials, there is an essential need to develop concrete made with a new kind of cement such as calcium aluminate cements (CAC), calcium sulfoaluminate cement (CSA), alkali-activated binders, and supersulfated cements (Juenger et al. 2011). Recently, CSA cement gained an increased attention due to its lower amount of $\mathrm{CO}_{2}$ emission as compared to that of OPC (Gartner 2004). It is reported that the $\mathrm{CO}_{2}$ emissions may drop by up to $35 \%$ if OPC is replaced with CSA cement (Berger et al. 2013). Additionally, concretes fabricated with CSA cement can result in an increased sulfate resistance, high impermeability and chemical resistance and a low chance for alkali-silica reactions (Tang et al. 2015).

Several benefits of HPC compared to conventional concretes have significantly increased its use in different structural applications. However, the brittleness of HPC is higher with respect to the normal-strength concrete due to the higher strength, which subsequently increases the vulnerability of HPC to the initiation and propagation of cracks of different sizes within the concrete body (Savino et al. 2018). The addition of discrete fibers in concrete is recognized as a suitable solution to overcome this weakness and develop materials with enhanced tensile strength, flexural strength, toughness, and thermal shock strength (Sanal et al. 2016; Afroughsabet et al. 2016, 2018; Cattaneo and Biolzi 2010; Simões et al. 2017). This study was aimed at analyzing the effects of CSA cement and DHE steel fibers on the engineering properties of HPC. Compressive strength, splitting tensile strength, flexural strength, modulus of elasticity, and microstructural observations were performed in order to evaluate the properties of concrete at different curing ages. The findings of this research are highly promising and show that the simultaneous use of CSA cement and DHE steel fibers can significantly increase the engineering properties of HPC. 


\section{Materials and Methods}

To explore the effects of CSA cement, GBBS and DHE steel fibers on the engineering properties of concrete, eight different concrete mixes were developed in this study. The concrete mixes included concretes containing 100\% OPC and 100\% CSA, 50\% OPC and 50\% CSA, 25\% OPC with 50\% CSA and 25\% GBBS without and with $1 \%$ DHE steel fibers. To assess the effect of curing age on the strength of concrete, the compressive strength tests were conducted at the ages of 1, 7, 28, and 56 days. Additionally, the splitting tensile tests were performed at 7, 28, and 56 days. All the other features of the concretes were evaluated at 28 days.

\subsection{Materials}

The binder materials used in this study were ASTM Type I Portland cement; CSA produced by Italcementi Group and ground granulated blast-furnace slag. Both natural sand, with a 2.9 fineness modulus, and crushed gravel, with a nominal maximum size of $19 \mathrm{~mm}$, were used as the aggregates at a volume fraction of $50 \%$. To achieve the desired workability in different concrete mixes, a Driver Care 10-Sika, was used as a superplasticizer. Additionally, in CSA cement-based concretes, tartaric acid was used as a retarder to increase the setting time of those mixes. Double hooked-end (DHE) steel fibers with a 60-mm length and an aspect ratio of 65 were employed in this study.

\subsection{Concrete Mixtures and Mixing Procedure}

The water-binder ratio was maintained at 0.35 and the water amount was $157 \mathrm{l}$ for all mixtures. A pan mixer was used for the preparation of all the mixes. Prior to adding the raw materials, the surface of the pan mixer was cleaned with a wet towel to avoid the absorption of aggregates moisture by the mixer. The mixing procedure, which was designed by trial, was chosen as follows: initially, the fine aggregate and cement were mixed for one minute. Afterward, approximately half of the water including SP was introduced into the mixer; the ingredients were further mixed for two minutes. The saturated surface dry (SSD) coarse aggregates and remaining mixing water were then introduced and the mixing was continued for another $5 \mathrm{~min}$. To fabricate uniform fiber-reinforced concrete, discrete fibers were added gradually to the rotating mixer and were mixed for an additional $5 \mathrm{~min}$ in order to obtain a homogenous concrete mix. Details of mix proportions and the results of a slump test are summarized in Table 1. The content of SP in that table is given as a percentage of the total mass of the binder. To determine the workability of fresh concrete, slump tests were performed as per ASTM C143 (2010) during the preparation of the concrete mixes. 





The specimens were molded with different dimensions that matched the requirements of their standard tests. The samples were covered with a wet plastic sheet to prevent them from dripping water in the first $24 \mathrm{~h}$ of curing. Then, the concrete specimens were demolded and immersed in lime-saturated water at $23{ }^{\circ} \mathrm{C}$ until reaching their testing ages. For each test, three samples were prepared, and the average value is reported as the final result.

\subsection{Testing Methods}

Compressive and splitting tensile strength tests were performed using a 3000-KN universal compression machine in accordance with ASTM C39 (2003) and ASTM C496 (2011), respectively. Cubic specimens $100 \mathrm{~mm}$ in size were used to determine the compressive strength, whereas cylindrical specimens with a diameter of $100 \mathrm{~mm}$ and a height of $200 \mathrm{~mm}$ were used to evaluate the splitting tensile strength of the concrete. The flexural strength tests were carried out as per EN 14651 (2007) on prismatic beams with dimensions of $150 \times 150 \times 600 \mathrm{~mm}$. The modulus of elasticity tests was conducted on the cylindrical specimens with dimensions of $100 \times 200 \mathrm{~mm}$ as per ASTM C469 (2014). To study the microstructure of concrete made with different types of binders, several images were taken from the fracture surface of concrete specimens by using scanning electron microscopy (SEM) method.

\section{Results and Discussion}

\subsection{Consistency}

The consistency of the different mixes developed in this study was evaluated by a slump test, and the results are shown in Table 1 . The slump values of the concrete varied between 19 and $23 \mathrm{~cm}$.

A minimum of $1 \%$ superplasticizer was required to adjust the consistency of concrete. Higher content of superplasticizer was used in CSA-based and in blended concretes compared to that of OPC to obtain an almost similar slump value. This can be explained by the fineness of CSA and a GBBS particle size that is lower compared to that of OPC. Furthermore, the fast rate of CSA cement hydration and its high demand of water to generate ettringite are other reasons that necessitate the addition of greater amounts of superplasticizer. The results further indicate that the incorporation of steel fibers had a negative influence on the properties of fresh concrete. The long steel fibers and aggregates interlock in the body of concrete and lead to a reduction in the slump value. To attain the same consistency in the concretes with and without fibers, the content of the superplasticizer was slightly increased. 


\subsection{Compressive Strength}

The compressive strength results of different mixes at curing ages of $1,7,28$, and 56 days are shown in Fig. 1.

The compressive strength of concretes containing CSA cement is significantly lower after 1 day compared to that of the OPC mix. This reduction at an early age can be explained by the presence of the retarder in the CSA concrete that postponed the formation of ettringite, and subsequently reduced the strength of the concrete. The full replacement of OPC with CSA cement led to a reduction in compressive strength of $55 \%$ after 1 day, while its strength at 7 days was slightly higher than that of the OPC concrete. It was also observed that the compressive strength of the CSA mix was increased by $10 \%$ and $12 \%$ after 28 days and 56 days, respectively, compared to that of the OPC concrete. The compressive strength of the concrete containing $50 \%$ OPC and 50\% CSA cement was lower than that of the reference OPC concrete at all the curing ages considered in this study (reduction of 42\%, 32\%, 21\%, and $13 \%$ at $1,7,28$, and 56 days of curing, respectively, compared to those of the OPC concrete). Similar to CSA concrete mix, the significant amount of strength reduction after 1 day is attributed to the presence of the retarder. However, the compressive strength has been increased at later ages as a result of the formation of ettringite (ye' elimite hydration) and also the hydration of alite and belite which are the main components of OPC. The lowest compressive strength at day 1 was achieved by the CSA-blend mix containing three types of binders (i.e., OPC25-CSA50-SL25 mix). However, compared to OPC concrete; the concrete compressive strength reduction is limited by aging (of about $80 \%, 28 \%, 15 \%$, and $9 \%$ at 1, 7, 28, and 56 days of curing, respectively). Introducing GGBS can result in an increase in the cohesiveness of the cementitious matrix, which reduces the formation of micro-cracks leading to an increased strength of concrete. Moreover, GGBS fills the capillary pores of the cement matrix and consequently improves the properties of the interfacial transition zone (ITZ), while the observed strength reduction at an early age (1 day) can be attributed to the lower hydration rate of concretes incorporating GGBS, which has
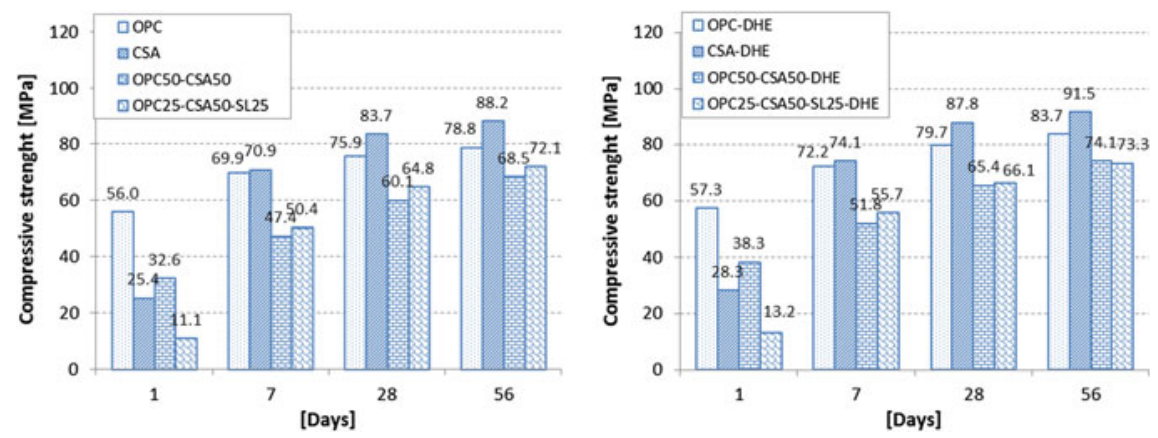

Fig. 1 Compressive strength 
been well documented in the literature (Celik et al. 2014). Concretes with steel fibers exhibited the same trend with a slight increase in compressive strength.

\subsection{Splitting Tensile Strength}

The splitting tensile strength results of different concrete mixes at curing ages of 7 , 28, and 56 days are shown in Fig. 2. The full replacement of OPC with CSA cement resulted in a slight reduction after 7 days, while after 28 and 56 splitting strength increased $(11 \%)$ with respect to OPC.

The strength reduction at 7 days can be attributed to the presence of the retarder which delayed the ettringite formation. However, at later ages of curing, a rich amount of ettringite was formed as a result of ye'elimite hydration, which consequently caused an improvement in the strength of concrete. The results further indicate that a combination of OPC and CSA cements at equal percentage of $50 \%$ led to a reduction in the splitting tensile strength of concrete at all curing ages considered in this study. For instance, the splitting tensile strength of the OPC50-CSA50 concrete reduced by $18 \%, 22 \%$, and $19 \%$ at 7,28 , and 56 days, respectively, compared to those of OPC. The incorporation of slag in OPC-CSA concrete led to an improvement in the splitting tensile strength, while its strength is lower compared to that of the reference OPC concrete. This increased strength can be attributed to the formation of additional C-S-H gel, particularly at later ages which is the main strength-contributing compound. Moreover, as observed for compressive strength, slag also fills in the capillary pores and improves the features of ITZ and microstructures of the cement matrix. It was noticed that the best performing mix was the CSA concrete which attained a 56-day splitting tensile strength of $4.77 \mathrm{MPa}$, while the lowest strength was gained by the OPC50-CSA50 concrete with strength of $3.47 \mathrm{MPa}$. The results of fiber-reinforced concrete indicate that the addition of $1 \%$ DHE steel fibers can significantly increase the splitting tensile strength of concrete. For instance, the splitting
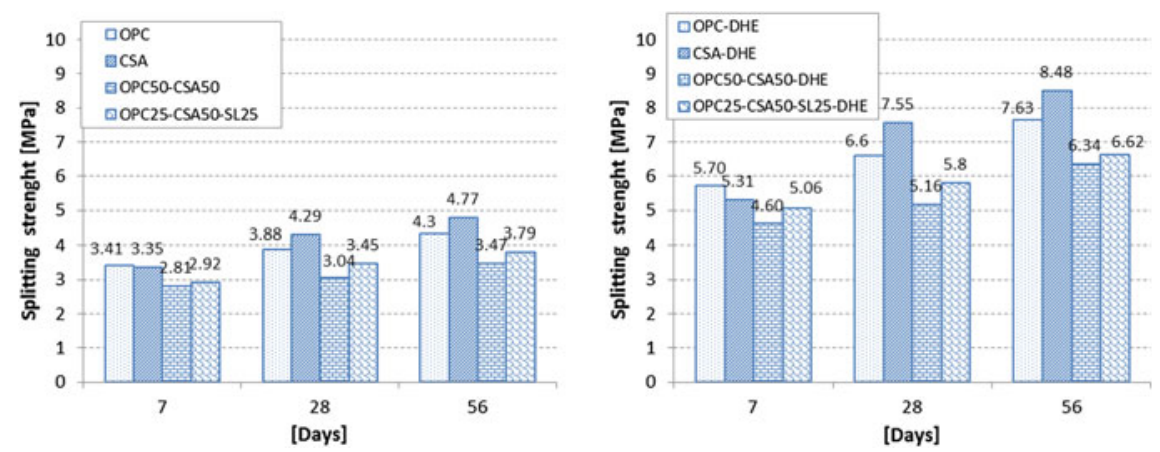

Fig. 2 Splitting tensile strength 
tensile strength of OPC-DHE1 concrete mix increased by $67 \%, 70 \%$, and $77 \%$ at 7 , 28 , and 56 days of curing, respectively, compared to those of OPC concrete. This improvement is attributed to the high tensile strength, elastic modulus, and effective anchoring mechanism of DHE steel fibers, which restrained the extension of macro-cracks in concrete (Afroughsabet et al. 2016). It was also observed that the simultaneous use of CSA cement and steel fibers was very effective in enhancing the splitting tensile strength of concrete, and the best performing mix was attained in the CSA-DHE concrete mix. The splitting tensile strength of the aforementioned mix was increased by $57 \%, 95 \%$, and $97 \%$ at 7, 28, and 56 days of curing, respectively, compared to those of OPC concrete. This improvement can be attributed to a more effective bond between the steel fibers and the CSA cement matrix due to self-stressing that resulted from the expansive behavior of CSA cement. The effect of curing age on the improvement of splitting tensile strength is relatively higher in FRC compared to plain concrete. For instance, the splitting tensile strength of CSA-DHE mix was increased by $42 \%$ and $60 \%$ at 28 and 56 days compared to its 7 -day strength, respectively, while the increase was $28 \%$ and $42 \%$ for CSA concrete, respectively.

\subsection{Modulus of Elasticity}

The 28-day modulus of elasticity of different concrete mixes is shown in Fig. 3. The results indicate that the cement type had a significant influence on the modulus of elasticity of the concrete. The full replacement of OPC with CSA cement caused an

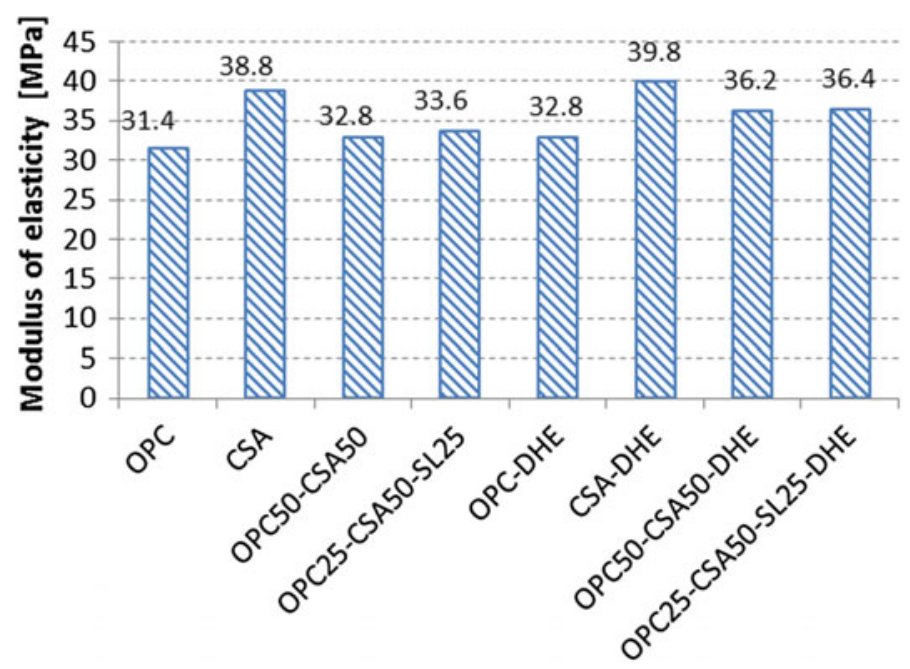

Fig. 3 28-days modulus of elasticity 
increase of $24 \%$ in the 28 -day modulus of elasticity. This increase can be explained by the ability of CSA cement to densify the microstructure of the cement matrix and improve the characteristics of ITZ, which consequently lead to an enhancement in the modulus of elasticity of concrete.

The combination of OPC and CSA cements at equal percentages of $50 \%$ led to a slight increase in the modulus of elasticity.

Additionally, the substitution of a portion of OPC with slag in CSA-blend concrete mix resulted in an increase of 7\% compared to that of OPC. The lowest modulus of elasticity was attained by the mix containing $100 \%$ OPC, while the best performing mix was the CSA mix, which attained a modulus of elasticity of $38.8 \mathrm{GPa}$.

The modulus of elasticity of OPC, CSA, OPC50-CSA50, and OPC25-CSA50SL25 concrete mixes containing 1\% DHE steel fibers were 4\%, 3\%, 10\%, and 8\% higher than those of the corresponding mixes without fibers, respectively. This result suggests that the addition of steel fibers with higher elastic modulus compared to that of the cement matrix can improve the modulus of elasticity of concrete.

\subsection{Flexural Behavior}

The diagram of the 28-day load-CMOD for different concrete mixes is shown in Fig. 4. The behavior of concretes without fibers was almost linear up to the maximum load, followed by a steeper descending branch up to failure point, and then the beam specimens split into two separated parts. The results indicate that the full replacement of OPC with CSA cement resulted in an increase of $20 \%$ in the maximum flexural load of concrete. Similar to the splitting tensile strength results, the rich

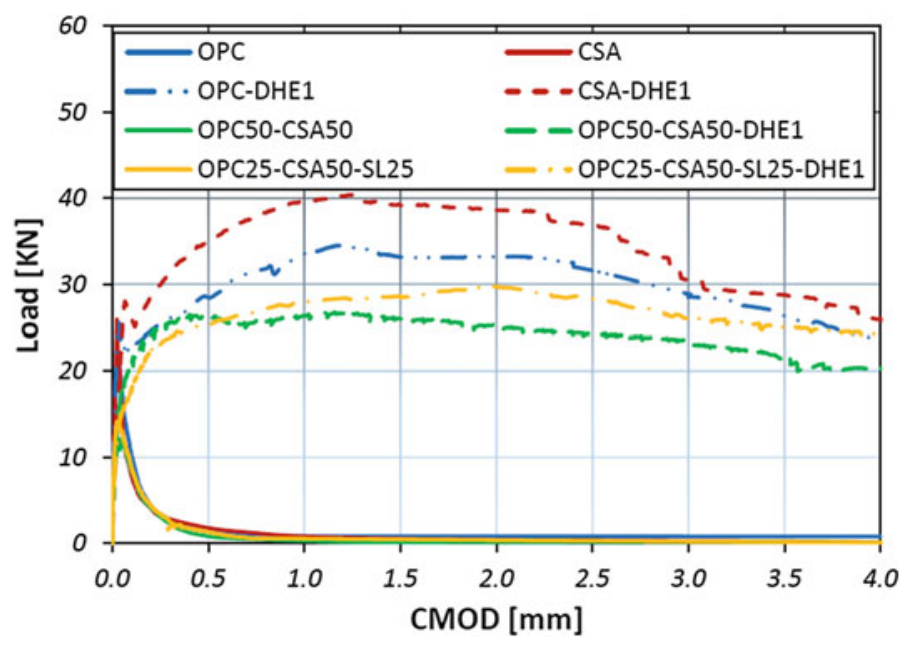

Fig. 4 Flexural load-CMOD curves 
amount of ettringite in this mix that was produced by hydration of ye'elimite, which is the main component of CSA cement, is the main reason for this improvement. It was also observed that the flexural strength of CSA-blend mixes was lower compared to that of the OPC mix. For instance, the flexural strength of OPC50-CSA50 and OPC25-CSA50-SL25 mixes were 44 and 35\% lower than that of the reference OPC mix. As can be seen, the replacement of OPC with $25 \%$ of slag caused an improvement in the flexural strength compared to that of the OPC50-CSA50 concrete. This improvement can be attributed to the formation of additional $\mathrm{C}-\mathrm{S}-\mathrm{H}$ gel which is the main strength-contributing compound as a result of the reaction between slag and calcium hydroxide. Moreover, slag may fill in the capillary pores and improve the features of transition zones and microstructures of the cement matrix.

On the other hand, the results of fiber-reinforced concretes illustrate that the addition of fibers remarkably improved the post-cracking behavior of FRC with an extensive cracking process between first crack load and peak load. It was noticed that the addition of $1 \%$ DHE steel fibers changed the behavior of concrete and a deflection-hardening performance was observed in all mixes reinforced with steel fibers. In these concrete mixes, once the first crack occurred, the fibers bridging the crack resisted the load and prevented further crack propagation. The excellent performance of these mixes can be attributed to the ability of DHE steel fibers to carry the load after matrix cracks until further cracks form. Figure 4 shows that the best performance was observed with the mix where OPC was fully replaced with CSA cement and reinforced with $1 \%$ steel fiber (i.e., CSA-DHE). The flexural strength of this mix increased by $87 \%$ and $55 \%$ as compared to that of the OPC and CSA concrete, respectively. The expansive behavior of CSA cement can lead to a better bond between the cement matrix and steel fibers, which subsequently led to an increase in the flexural strength of concrete. The results further show that the flexural strength of OPC, CSA, OPC50-CSA50, and OPC25-CSA50-SL25 mixes containing $1 \%$ DHE steel fibers was increased by $60 \%, 55 \%, 120 \%$, and $113 \%$, respectively, as compared to that of their corresponding mixes without fibers. As it can be observed in the graph, the inclusion of steel fibers had the most influence on the flexural strength of concrete where CSA cement was used in blend mixes. As previously mentioned, the expansive behavior of CSA-blend mixes may lead to a better bond between the cement matrix and steel fibers as a result of self-stressing, which subsequently leads to an increase in the flexural strength of concrete.

\subsection{SEM Observation}

To study the microstructural properties of concretes fabricated with different binders, an SEM method was used and images of the fracture surface are shown in Fig. 5. As one can observe, the hydration products of OPC concrete consist of a featureless gel of $\mathrm{C}-\mathrm{S}-\mathrm{H}$, ettringite crystals with a needle-like shape, and calcium hydroxide $(\mathrm{CH})$ crystals with a plate-like shape. The results indicate that the content of calcium hydroxide is relatively higher than that of the ettringite. Additionally, it can 

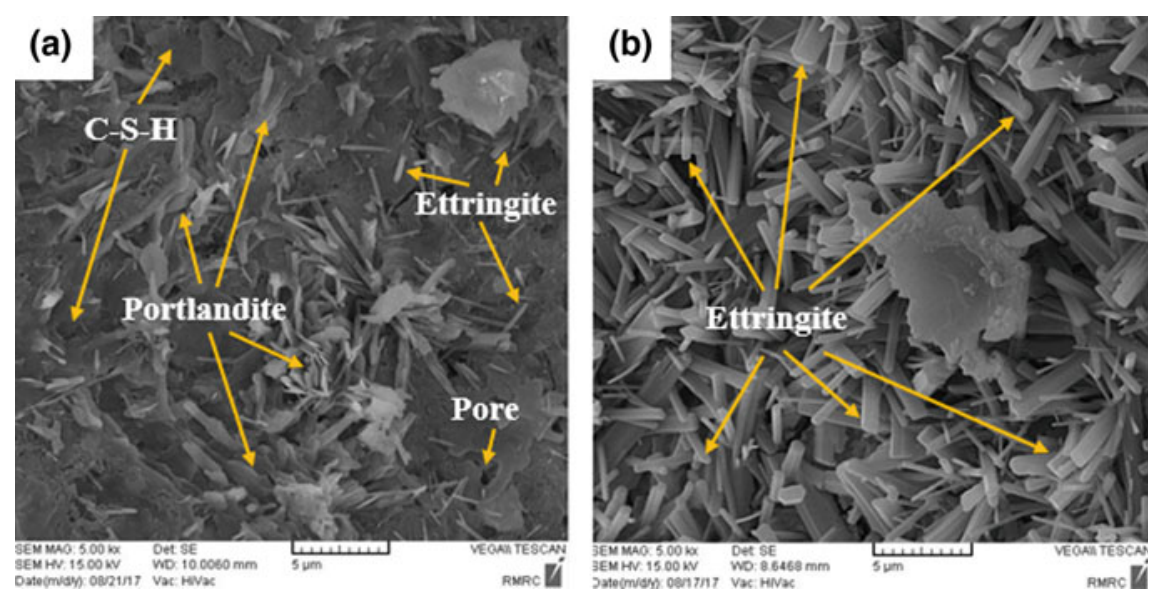

Fig. 5 SEM images: a OPC b CSA concrete

be seen that the length of ettringite crystals developed in OPC concrete varied from 1 to $3 \mu \mathrm{m}$. Moreover, there are pores in the surface of the cement matrix that can adversely affect the durability properties of concrete. Figure $8 \mathrm{~b}$ shows the hydration products of CSA cement-based concrete, which mainly consist of prismatic ettringite crystals of different sizes. This type of ettringite crystals causes an improvement in the mechanical properties of concrete and also leads to the dimensional stability of cement (Arjunan et al. 1999).

\section{Conclusions}

The following conclusions can be drawn from the experimental results: the slump values of all concretes considered in this study varied from 19 to $23 \mathrm{~cm}$. However, a greater dosage of superplasticizer was used in CSA cement-based concretes to achieve a similar consistency to that of the OPC mixes. The addition of steel fibers adversely affects the consistency of concrete. The full replacement of OPC with CSA cement results in an increase in the mechanical properties of concrete particularly at later ages. This can be attributed to the formation of a rich amount of ettringite crystals which, due to the interlocking effect, improve the mechanical properties of concrete. The results also indicate that the strength evolutions of CSA cement-based concretes are higher compared to those of OPC mixes. The addition of $1 \%$ DHE steel fibers in concrete significantly increases the mechanical properties of concrete, especially the splitting tensile and flexural strengths of concrete. For instance, the splitting tensile and flexural strengths of the OPC-DHE1 mix after 28 days were increased by 70 and $61 \%$ over those of the OPC mix. These increases for the CSA-DHE1 mix compared to those of the CSA mix were 76 and 55\%. Moreover, the addition 
of $1 \%$ DHE steel fibers in concrete results in a deflection-hardening behavior. The SEM results indicate that the hydration products of OPC concrete mix are mainly consist for portlandite, while prismatic ettringite crystals are the main products of CSA cement-based concrete.

\section{References}

Afroughsabet, V., Biolzi, L., \& Ozbakkaloglu, T. (2016). High-performance fiber-reinforced concrete: a review. Journal of materials science, 51(14), 6517-6551.

Afroughsabet, V., Biolzi, L., \& Monteiro, P. J. (2018). The effect of steel and polypropylene fibers on the chloride diffusivity and drying shrinkage of high-strength concrete. Composites Part $B$ Engineering, 139, 84-96.

Arjunan, P., Silsbee, M. R., \& Roy, D. M. (1999). Sulfoaluminate-belite cement from low-calcium fly ash and sulfur-rich and other industrial by-products. Cement and Concrete Research, 29(8), $1305-1311$.

ASTM, C 39. (2003). Standard test method for compressive strength of cylindrical concrete specimens.

ASTM, C 143. (2010). Standard test method for slump of hydraulic-cement concrete.

ASTM, C 496. (2011). Standard Test Method for Splitting Tensile Strength of Cylindrical Concrete Specimen.

ASTM, C 469. (2014). Standard test method for static modulus of elasticity and Poisson's ratio of concrete in compression.

Berger, S., Aouad, G., Coumes, C. C. D., Le Bescop, P., \& Damidot, D. (2013). Leaching of calcium sulfoaluminate cement pastes by water at regulated $\mathrm{pH}$ and temperature: experimental investigation and modeling. Cement and Concrete Research, 53, 211-220.

Cattaneo, S., \& Biolzi, L. (2010). Assessment of thermal damage in hybrid fiber-reinforced concrete. ASCE Journal of Materials in Civil Engineering, 22(9), 836-845.

Celik, K., Meral, C., Mancio, M., Mehta, P. K., \& Monteiro, P. J. M. (2014). A comparative study of self-consolidating concretes incorporating high-volume natural pozzolan or high-volume fly ash. Construction and Building Materials, 67, 14-19.

EN 14651. (2007). Test method for metallic fibre concrete-measuring the flexural tensile strength (limit of proportionality (LOP), residual).

Gartner, E. (2004). Industrially interesting approaches to "low- $\mathrm{CO}_{2}$ " cements. Cement and Concrete Research, 34(9), 1489-1498.

Gartner, E., \& Hirao, H. (2015). A review of alternative approaches to the reduction of $\mathrm{CO}_{2}$ emissions associated with the manufacture of the binder phase in concrete. Cement and Concrete Research, $78,126-142$.

Juenger, M. C. G., Winnefeld, F., Provis, J. L., \& Ideker, J. H. (2011). Advances in alternative cementitious binders. Cement and Concrete Research, 41(12), 1232-1243.

Şanal, İ., Özyurt, N., \& Hosseini, A. (2016). Characterization of hardened state behavior of self -compacting fiber-reinforced cementitious composites (SC-FRCC's) with different beam sizes and fiber types. Composites Part B Engineering, 105, 30-45.

Savino, V., Lanzoni, L., Tarantino, A. M., \& Viviani, M. (2018). Simple and effective models to predict the compressive and tensile strength of HPFRC as the steel fiber content and type changes. Composites Part B Engineering, 137, 153-162. 
Simões, T., Octávio, C., Valença, J., Costa, H., Dias-da-Costa, D., \& Júlio, E. (2017). Influence of concrete strength and steel fibre geometry on the fibre/matrix interface. Composites Part B Engineering, 122, 156-164.

Tang, S. W., Zhu, H. G., Li, Z. J., Chen, E., \& Shao, H. Y. (2015). Hydration stage identification and phase transformation of calcium sulfoaluminate cement at early age. Construction and Building Materials, 75, 11-18.

Open Access This chapter is licensed under the terms of the Creative Commons Attribution 4.0 International License (http://creativecommons.org/licenses/by/4.0/), which permits use, sharing, adaptation, distribution and reproduction in any medium or format, as long as you give appropriate credit to the original author(s) and the source, provide a link to the Creative Commons license and indicate if changes were made.

The images or other third party material in this chapter are included in the chapter's Creative Commons license, unless indicated otherwise in a credit line to the material. If material is not included in the chapter's Creative Commons license and your intended use is not permitted by statutory regulation or exceeds the permitted use, you will need to obtain permission directly from the copyright holder. 